\title{
AN ESSAY ON PHILOSOPHY, MATHEMATICS AND CULTURE
}

\author{
UM ENSAIO SOBRE FILOSOFIA, MATEMÁTICA E CULTURA
}

Ubiratan D'Ambrosio ${ }^{1}$

\begin{abstract}
The theme of this collection of essays has two elusive concepts, philosophy and mathematics, and the same for the combination of the two, Philosophy of Mathematics. I discussed the evolution of mathematics as an human endeavor, with a holistic historiographic stance. My tactics throughout the chapter was to examine the evidence for the creation of more or less systematic inquiries in different societies and at different periods, to investigate why they were defined or understood in the ways they were, on what basis particular individuals or groups claimed special expertise, and what lead to a professionalization.
\end{abstract}

Key-words: Philosophy; Mathematics; Philosophy of Mathematics; Holistic historiographic.

Resumo: O tema desta coleção de ensaios tem dois conceitos alusivos: filosofia e matemática e as mesmas para a combinação de ambos: Filosofia da Matemática. Eu discuti a evolução da matemática como um esforço humano com postura historiográfica holística. Minha tática ao longo do capítulo foi examinar as evidências para a criação de inquéritos mais ou menos sistemáticos em diferentes sociedades e em diferentes períodos, para investigar por que eles foram definidos ou entendidos da maneira que foram, com base em que indivíduos ou grupos particulares reivindicaram especial expertise, e o que leva a uma profissionalização.

Palavras-chave: Filosofia; Matemática; Filosofia da Matemática; Historiografia holística.

\section{Introduction}

The theme of this collection of essays has two elusive concepts, philosophy and mathematics, and the same for the combination of the two, Philosophy of Mathematics. How to conceive Philosophy, Mathematics and Philosophy of Mathematics and of the Sciences in general? My approach is etymologic and in a certain way it is tautological. The word philosophy is traced to the Greek philosophia 'love of wisdom' and the word mathematics also to the Greek máthema (from mathein, the verb "to have learned") meaning "learnable things". From that mathèmatikós, meaning "related to learning" or "studious," which gave origin to mathèmatiké tékhnē and the Latin ars mathematica, as used by Cicero, which was absorbed by medieval scholars. Nothing to do with our current use of the word Mathematics, which, in the sense we use today, appeared only in early Renaissance.

\footnotetext{
${ }^{1} \mathrm{PhD}$ in Mathematics from the University of São Paulo (USP). Permanent Professor of the Graduate Program in Mathematical Education at the Paulista State University "Júlio de Mesquita Filho" (UNESP), Rio Claro, São Paulo, Brazil. E-mail: ubi@usp.br
} 
In general, we recognize Philosophy as the mental strategies (abstract) to critically understand and explain how the human species developed ways to cope with the natural and social environment (to survive) and to understand and explain reality (cosmic, natural and emotional), mythology and ontology, aesthetic and ethics (to transcend survival). Mathematics are strategies (concrete and abstract) developed by the human species with the same objectives. As mentioned above, the terms were coined by Greeks and incorporated by Western traditions. There is an intense dispute if strategies of thought, both abstract and concrete, in non-Western traditions can be accepted as philosophy and as mathematics. The root of this dispute lies in the assumption that in different traditions elites organize their thoughts about doing and knowing as disciplines and specialists. It is generally claimed that in Western traditions this is made in a clear, unequivocal and standard way. This is well discussed by G.E.R. Lloyd in his book Disciplines in the Making. When discussing about Medicine, Lloyd look into non-Western traditions and to individual men or women reputed to have special powers for good or evil, including in matters of diseases and their cures, calling them shamans, which constitute the elites in their communities. He has a memorable phrase:

\begin{abstract}
alternative styles of medicine, with their more or less articulate elites to promote them, are likely to continue to bear witness to the complexities of our understanding of what it is to be truly well, and it would surely be foolhardy to suppose that biomedicine has nothing to learn from its rivals (LLOYD, 2009, p. 92).
\end{abstract}

In the literature we find hundreds of definitions for each of these concepts. While noticing that most are very similar, merely rewording the same ideas, I dare to add another definition trying to propose a novel approach. Since Antiquity, in all civilizations and cultures, elites organized their thoughts in disciplines. I discuss this by introducing the word ethnomathematics as a construct: tics + mathema + ethno, the result of committing

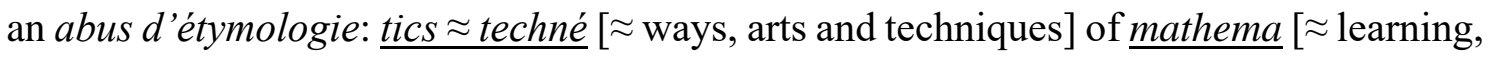
understanding, explaining] in different ethno $[\approx$ natural, socio-cultural, emotional environment]. Ethnomathematics was initially conceived as a research program in the History and Philosophy of Mathematics in connection with all areas of knowing and doing everywhere in the World. Later, this became more ambitious, aiming at being a theory of knowledge. Obviously, this ambitious program is transdiciplinary and transcultural an I will elaborate on it below (D’AMBROSIO, 1985). 


\section{The Program Ethnomathematics}

The Program Ethnomathematics is a research program focused in the question of how the human species developed their means for surviving and for transcending realty. It relies on the analyses of the history of ideas and of the evolution of behavior and knowledge of the human species, in every natural and socio-cultural environment. Although the Program Ethnomathematics initially contemplated the History and Philosophy of Mathematics and has, as a consequence, the obvious pedagogical implications (D'AMBROSIO, 1992), its focus grew to contemplate the complex system of knowledge and behavior generated and organized by both each individual (from birth to death) and all the human species. Both, as the human species in general, develop strategies to cope with the ample reality as stated in the preamble. As it will become clear in this paper, Ethnomathematics is not a final theory, and this is the reason for calling my proposal a research program.

From this very beginning, I consider very important to clarify that my concept of Ethnomathematics is much more ambitious than the study of mathematical ideas and techniques recognized in different ethnic groups and in artisanship and professional practices and even in different civilizations, as it is the main focus of ethnography and ethnology.

I understand Mathematics as broad category which is an abstract construct originated in the cultures of the Mediterranean Basin and the Mesopotamic (Ancient Iraq) and Nile valley civilizations. We might say that Academic (School) Mathematics is the Ethnomathematics of that region. This category of knowledge is sometimes referred as the Euclidean style and it is supported by tertium-non-datur, is insufficient and even inadequate as a strategy to deal with facts and phenomena of other different natural and socio-cultural environments. As we learn from eminent historian of mathematics $\mathrm{Wu}-$ Wen Tsun, ancient mathematics in China had a different method of thinking and style of presentation of Greek mathematics (WEN-TSUN, 1986).

We recognize similar abstract constructs when we study the History of Mathematics in Ancient India, in the Andean civilizations, in Sub-Sahara Africa, in Polynesia, indeed in every civilization in the world. There may be some similitude in the abstract constructs in different civilizations, but they are essentially distinct. We have to understand the intellectuals, the artisans, the professionals, the people, the invisible society in these regions, their myths and systems of value, their knowledge systems. All 
are in permanent change. We have also to consider the dynamics of the encounters of civilizations.

As it has been repetitiously explained, I use the prefix ethno in a much broader sense than ethnic and also mathema and tics in a different meaning than in the academic discipline Mathematics,

The Program Ethnomathematics is conceptually designed as a broad research program of the evolution of ideas, of practices and of knowledge in the human species in different cultural environments. Essentially, it implies an analysis of how groups of humans generated ways, styles, arts and techniques of doing and knowing, of learning and explaining, of dealing with situations and of solving problems of their natural and socio-cultural environment. I practiced an etymological abuse with the "free" appropriation of Greek roots: techné [tics] meaning ways, styles, arts and techniques; mathema for doing and knowing, for learning and explaining, for dealing with situations and solving problems; and ethno, as distinct and specific natural and socio-cultural environment. Thus, using these Greek roots, I synthesized as tics + mathema + ethno the way groups of humans generated ways, styles, arts and techniques of doing and knowing, of learning and explaining, of dealing with situations and of solving problems of their natural and socio-cultural environment. It is easy to understand how this conceptual etymological construction gave origin to the word ethnomathematics. Although the words ethnobotany, ethnomusicology, ethnolinguistic, ethnomethodology and other ethno+disciplines are used by anthropologists, by ethnographers and by sociologists for research of specific disciplines in different ethnic and social contexts, they base their research on the views of an observer of other cultures, trying to find commonalities between the culture of the researcher and of the researched. My appropriation of the prefix ethno is very different. The conceptual way I introduced ethno+mathema+tics recognizes specific cognitive strategies of a culture to deal with reality. For example, it does not make sense to address different ethnic groups asking questions such as "what is the meaning of a triangle?" or "how would you add 2 plus 3 ?" or "what is the color of this flower?" The categories triangle, 2 plus 3, color may be absolutely senseless in their culture. Very illustrative of this remark is the research on the piraha culture in the Amazon Basin conducted by Daniell L. Everett. This research is related to the intriguing question of mutual influences of culture and cognition. ${ }^{2}$ My appropriation of the concept

${ }^{2}$ A synthesis of this research is in the book of Daniel L. Everett: Don't sleep, there are snakes. Life and Language in the Amazonian Jungle, New York: Vintage Books, 2009. 
of mathema as a philosophical category is fundamental. I claim that there are different ways of doing the equivalent of "mathematics" in different cultures.

The etymological abuse makes clear that to do research in the Program Ethnomathematics we must dialogue with ethnic group, with the intellectuals, the artisans, the professionals, the people, the invisible society. A research methodology of the Program Ethnomathematics consists essentially of the steps:

- How do ad hoc practices and solution of problems develop into methods?

- How do methods develop into theories?

- How do theories develop into scientific invention?

I will not give examples of how this methodology is practiced. This can be seen in innumerous publications in the area. ${ }^{3}$ But I move into theoretical reflections that support the Program Ethnomathematics.

The study of Mathematics, as well as all the disciplines and of cognition in general is of interest to philosophers and vice versa, since one of the main philosophical task is to reflect upon the basic assumptions, inference, patterns and theories.

I owe much to Imre Lakatos. In his seminal paper History of Science and its Rational Reconstructions (Lakatos, 1971), first sentence is his classical citation

Philosophy of science without history of science is empty; history of science without

$$
\text { philosophy of science is blind. }
$$

He says this is a paraphrase of Kant. Lakatos starts from the premise that knowledge does grow, suggesting that the task of the philosopher is extracting rationality from historical developments. History must be viewed as a repository of more than facts, names, dates, places and anecdote. A broader concept of historiography is needed.

I discuss the evolution of knowledge and behavior with a holistic historiographic stance. There are numerous conceptions and definitions of knowledge and behavior. Mine: $\bullet$ knowledge is the set of strategies to survive and to transcend; $\bullet$ behavior is the manifestation of knowledge. Knowledge and behavior evolve through a slow, fragmented, holistic, transdisciplinary and transcultural process. It is an adaptive system, which gradually transforms its own cognitive and social bases, to satisfy the pulsion of survival, and, uniquely in the human species, the pulsion of transcendence. The dyadic

\footnotetext{
3 I refer to the Dossier on Ethnomathematics published in https://periodicos.sbu.unicamp.br/ojs/index.php/etd/issue/view/1404/showToc as a collection of articles in the electronic journal ETD - Educ. Temat. Digit., Campinas (SP) - v. 19, n. 3 (2017), (ISSN 1676-2592; DOI: 10.20396/etd.v19i3.8648367).
} 
relationship between knowledge and behavior, as well as between survival and transcendence, is a closed and self-explanatory unit of natural, cultural and social reality, which we might call consciousness. It is responsible for defining strategies of action, aiming at reducing our reliance on trial and error to solve problems and face situations. Consciousness also helps to predict consequence of our action. It is a state of awareness that emerged in the evolution of all the species.

\section{Reflections on history}

Facts, phenomena and events are all that happened. Like the chronicler of everyday life, the historian uses multiple sources that report and describe facts, phenomena and events, interpret them, inevitably giving space for his imaginary, and thus write history. The historian not rarely appeals to his personal ideology in order to justify the present (LEWIS, 1975).

To adopt a holistic approach, which analyzes complex systems of facts, phenomena and events as an interconnected, coherent and contextualized whole, contrasts with the purely analytical tradition commonly adopted in academia, which is a reductionism that aims to gain understanding of complex systems by dividing them into smaller elements of composition and gaining an understanding of the elementary properties of their components. The holism-reductionism dichotomy has been permanent throughout history. In opting for the holistic approach, I am adopting a transdisciplinary and transcultural stance. Support for the holistic approach is manifold. I like the General Systems Theory proposal, as presented by Kenneth Building:

\footnotetext{
Mathematics attempts to organize highly general relationships into a coherent system, a system however which does not have any necessary connections with the "real" world around us. It studies all thinkable relationships abstracted from any concrete situation or body of empirical knowledge. It is not even confined to "quantitative" relationships narrowly defined - indeed, the developments of a mathematics of quality and structure is already on the way, even though it is not as far advanced as the "classical" mathematics of quantity and number. Nevertheless because in a sense mathematics contains all theories it contains none; it is the language of theory but it does not give us the content. At the other extreme we have the separate' discipline we have separate disciplines and sciences, with their bodies separate from theory. Each discipline corresponds to a specific segment of the empirical world, and each develops theories that have particular applicability to its own empirical segment. Physics, chemistry, biology, psychology, sociology, economics and so they all carve out certain elements of man's experience and develop theories and patterns of activity (research) that produce satisfaction of understanding and are appropriate for their special segments (BOULDING, 1956, p. 1).
} 
This is similar to what I call, in some of my works, epistemological cages, comparing experts to birds living in a cage. The birds only see and feel what the bars allow, they only feed on what they find in the cage, they only fly in the space of the cage, they only communicate in a language known to them, they breed and reproduce in the cage. But they don't know what color the cage is painted on the outside (D'AMBROSIO, 2016).

We can choose a level of construction of an intermediate type between the highly generalized constructions of pure mathematics and the specific constructions of specialized disciplines. Mathematics tries to organize highly general relations in a coherent system, a system that has no necessary connection to the "real" world around us. Mathematics studies all thinkable relationships abstracted from concrete situations or empirical knowledge. It goes beyond strictly defined quantitative relations and dares to resort to qualitative relations. The preponderance of formalism in the mathematical narrative is exemplified by the enigmatic statement of David Hilbert, which is part of mathematical folklore (BLUMENTHAL, 1935). He would have said, in a circle of friends in a brewery, something like:

I can build Geometry starting not from a point, straight and flat, but from tables, chairs and glasses of beer.

With this joke, Hilbert meant that axioms are not taken as self-evident truths. Geometry can deal with things about which we have powerful intuitions, but it is not necessary to assign any explicit meaning to indefinite concepts. It is important to discuss their defined relationships, that is, the relationships between objects and not the essence of objects. Objects are organized as elements of a theory. Mathematics addresses the language of the theory, but not the content of the theory.

In the formalistic approach, as exemplified by Hilbert's dictum, there is no place for other modes of thought, like natural sciences and the arts, and the cognitive process privileges precision and rigor. If we want a broader look, giving meaning to the contents of the theoretical propositions and relating them to reality, we found this in non-Western cultures. In other words,

If philosophy in the West no longer occupies a privileged, foundational position with respect to other cultural activities such as science or art, then a full appreciation of philosophy and its importance for human experience requires that we examine the role of philosophy in cultures other than our own (VARELA; THOMPSON; ROSCH, 1991, p. 21). 
This is particularly relevant when we want to discuss mathematics as a humanistic endeavor, supported by the theory of Embodied Mind, which has convergence of ideas proposed by Martin Heidegger, Maurice Merleau-Ponty, Michel Foucault, Jacques Derrida, Pierre Bourdieu and contemporaries. It encompasses both the body, as an accumulation of lived experiences, and the mind, as the context of cognitive processes. Human history shows that experiences, as well as skills, are transmitted and accumulated through generations and are refined in this process. These constitutes the traditions, a major component of culture. Embodied Mind offers a cognitive support for the Program Ethnomathematics, which was briefly introduced above.

Every individual is obsessed with understanding the other and understanding and explaining events, facts and phenomena. This is typical of human nature. Understanding implies the action of observing, the result of intellectual contemplation, such as seeing a show or participating in a party. It is an art that usually results in a rhetorical reaction of rejection or continence, often giving rise to a practice in the service of politics, morality, philosophy, religion, health and other interests. Who seeks to understand is clearly aware, projects his concerns and highlights important events, even though his underlying causes and determinants were below the level of understanding of his contemporaries, who sometimes were not aware, but who involuntarily dealt with its consequences. But there are events, facts and phenomena that, although they escaped observation and were not recorded in the documentation of the time, they are part of the cultural memory and traditions of the peoples. These two categories of events, facts and phenomena are what historian Bernard Bailyn calls manifest history and latent history (BAILYN, 1982). Historians of the present have more views of the old than the new, they look to the present using their knowledge of the past.

Historiography is like quicksand. It is a set of oral and written narratives, some true, many the result of deception and self-deception, other narratives are lies, able to involve any reader and researcher who wants to probe this set of materials. The academic world proclaims this survey, but it often privileges deception, deliberate falsehood and direct forgery, which later proves to be a myth. Forgery is a mean to achieve political ends in society in general and in the academy itself, where their performance, reliability and veracity are evaluated by their own peers.

An example of forgery involves distinguished French geometer Michel Floréal Chasles (1793-1880), who, in 1867, presented to the Académie des Sciences correspondence between Newton, Pascal, and Boyle, and published papers citing them, 
which Chasles claimed to be a "proof" that Pascal was the first to propose the universal law of gravitation, and not Newton. This would imply that the naissance of Modern Science was France, not in England, which would be a victory in the conflict between the two nations. Afterwards, Chasles revealed that the letters were bought of Denis VrainLucas (1818-1882), a law clerk who decided to forge letters and other documents and sell them to manuscript collectors. If it is hard to understand how Chasles fell for these forgeries, it is even harder to understand how such an highly intelligent man fell for some of the other forgeries that Vrain-Lucas sold him. This is an ongoing discussion by historians (ALDER, 2004).

Sometimes instead of forgery we have concealing of facts, phenomena and events. This is close to the historiographical proposal of Bernard Bailyn. This is well discussed in Mercedes Garcia Arenal in her essay-review of a book by Katrina B. Olds (2017). A good example is how Isaac Newton studies of theology, by far more numerous than his publications on Mathematics and Physics, have been concealed. The reasons for this were political and ideological. This concealment is now drawing attention of Newton's scholars. According to Rob Iliffe

In November 1679 the secretary of the Royal Society, Robert Hooke, wrote to
Isaac Newton to ask his views on a number of recent scientific theories and
discoveries. ... He told Hooke that having spent the last few months in the
country, he was completely unaware of what natural philosophers in London
or anywhere else had been doing. His disillusionment with philosophy had
been brewing for some time, he said, and he added that he had been trying for
many years to turn away from the natural sciences. Now, he continued, he
wanted to concentrate on his "other studies." He had "shook hands" with
natural philosophy and was as uninterested in the subject as any rustic was,
about scholarly pursuits. Instead, he was going to concentrate on research that
he enjoyed, or that was of benefit to others (ILIFFE, 2017, p. 3).

Curiously, this was very early in his career. Newton was 36 years old and the Philosophiae Naturalis Principia Mathematica was practically finished, published a few years later, in 1687, by insistence of his friend Edmond Halley (1645-1742).

Examples of forgery and concealment pose problems for historiography, since they reveal a process of social construction of truth and also of efforts to achieve political ends, both for an individual, for a group or party and for a country. Another example is the Trofim Denisovich Lysenko (1898-1976) affair. Similar cases involving mathematicians in the former Soviet Union and elsewhere are well known. The background of history is not just what is narrated orally or in writing, what was published, but it is a complex of everything that intervenes in a fact, in an event. Reflecting on these issues, we are led to question the nature of an action and the interests and intentions of it. 
Every action implies the new, which does not necessarily mean that what existed before must be removed or destroyed, and that things as they were before must be denied. Unfortunately, when proposing the new, the agent, by mistake and self-deception or by deliberate lying, ignores or even denies and proposes to destroy what was before. This situation is evident in the process of conquest and colonization and in the current practices of globalization. It also occurs in scholarship.

Philosophy can never be reduced to mathematics. Philosophers try to recognize the mental strategies (abstract) to critically understand and explain how individual mathematicians advanced in their strategies (concrete and abstract) to reflect upon facts and ideas about the natural, social, cosmic and emotional environment, motivated by mythology and ontology, aesthetic and ethics and even the imaginary and fantasia transcending survival. Mathematics are strategies (concrete and abstract) developed by the human species with the same objectives.

Everyone who did research in mathematics knows how much paper is crumpled before reaching the final version of a proposition. Even after publishing, the final version may go through many drafts and revisions. This is true in all our actions. Doing and then reflecting on what has been done, normally leads to improvement. Critics will say that this is an exceedingly simple - even naïve - way of understanding the evolution of knowledge.

Many claim that Mathematics depend on experiences, intuition, precision, rigor and aesthetics. Timothy Williamson, in his book with the challenging title The Philosophy of Philosophy, presents a general view of Mathematics:

past experience of spatial and temporal properties may play a role in skilful mathematical "intuition" that is not directly evidential but far exceeds what is needed to acquire the relevant mathematical concepts. The role may be more than heuristic, concerning the context of justification as well as the context of discovery. Even the combinatorial skills required for competent assessment of standard set-theoretic axioms may involve off line applications of perceptual and motor skills, whose capacity to generate knowledge constitutively depends on their honing through past experience that plays no evidential role in the and assessment of the axioms (WILLIANSON, 2007, p. 168).

Beyond rigor and precision, mathematics has less obvious values to teach. In particular, a mathematical training makes one appreciate the importance of the aesthetics of definitions. Experience shows that a mathematician or logician with no ability to discriminate between fruitful and unfruitful definitions is unlikely to achieve much in research. Such discriminations involve a sort of aesthetic judgment. The ugly, convoluted, ramshackle definitions of concepts and theses that philosophers seem to feel no shame in producing are of just the kind to strike a mathematician as pointless and sterile. Of course, it is notoriously hard to explain why aesthetic criteria are a good methodological 
guide, but it would be dangerously naïve to abandon them for that reason (WILLIANSON, 2007, p. 269).

This occurs in the evolution of mathematics, physics, other sciences, myths and religions, arts and social behavior in general. I must confess that I owe much to Jean Piaget in his classic L'Epistémologie Génétique and his works on Education, as well as by many authors on Stories of Civilizations and the History of Ideas in general.

Once again committing an abus d'étymologie, I might use the prefix meta and say metaphilosophy, metaphysics, metamathematics, metamythology, metaart and so on, a mere exercise of words. The terms metaphysics and metamathematics are consecrated, in a very elaborate sense, by academic experts, and became disciplines in their own. Nothing to do with the way in which I might have used the meta prefix in my proposal of a theory of knowledge. Instead of meta I opt for trans (beyond, across, over) and inspired by Sigmund Freud, I call the pulsion of survival which manifests as doings and the pulsion of transcendence which manifests as knowing. The pulsion of survival, by many called instinct, are the quintessence of living creatures since the Darwinian LUCA (Last Universal Common Ancestor). The acquisition of the pulsion of transcendence is a great challenge in the theory of evolution. This transition results from the emergence of awareness and consciousness, elusive concepts, related to specifics differentiation in the composition of the brain and the nervous system. Very curiously, research on the early appearance of consciousness can be traced back to insects, to underwater invertebrates and other forms of living beings. How some forms of consciousness are present in bees was discovered in 1945 by Karl von Frisch (Nobel Prize in Physiology or Medicine). Early composition of the brain and of the nervous system in octopus was studied in 1982, by Martin Moynihan and Arcadio Rodaniche, as detailed in a recent book by Peter Godfrey-Smith (2016).

The octopus is sometimes said to be a good illustration of the importance of a theoretical movement in psychology known as embodied cognition. These ideas were not developed to apply to octopuses, but to animals in general, including ourselves, and this view has also been influenced by robotics. One central idea is that our body itself, rather than our brain, is responsible for some of the "smartness" with which we handle the world. Our body's own structure encodes some information about the environment and how we must deal with it, so not all this information needs to be stored in the brain. 
It is a matter of cognition. What mental structure is responsible for knowing, creating and behaving? It is the central theme of neurocognition and cyberneticscience. The predominant Philosophy of Mathematics ignores these new sciences.

Philosophy of Mathematics is organized along lines known as Pragmatism, Logicism, Intuitionism, Forrmalism, Predicativism, Platonism and many others. Most scholars on the Philosophy of Mathematics elaborate on classics of these lines, and the same is true for most scholars in all the academic disciplines. They act like what Schopenhauer calls book-philosophers:

\begin{abstract}
The book-philosopher [...] reports the statement of one man has said, the opinion of another and the objection of a third and so on. He compares, carefully weighs, criticizes all these and endeavours to get at the truth of the things (Schopenhauer, 1974, p. 496).
\end{abstract}

This does not mean disregarding previous philosophers. But adhering to an established research line and to an author, although being a critical adherence, may limit an ample vision of the subject.

This is valid. But new visions are needed. The recognition and acceptance of elites of the disciplines has been practiced in scholarship since antiquity and remains in the current academic landscape. In a way, it explain the traditional phrase of seeing better if standing on giant shoulders, which is attributed, by John of Salisbury (c.1110-c.1180) in his Metalogicon, 1159, to Bernard de Chartres (?-died c.1160):

Bernard of Chartres used to compare us to [puny] dwarfs perched on the shoulders of giants. He pointed out that we see more and farther than our predecessors, not because we have keener vision or greater height, but because we are lifted up and borne aloft on their gigantic stature. ${ }^{4}$

\title{
4 Knowledge and mathematical behavior
}

I venture to follow a research line which does not fit in the traditional ones, by reflecting on the evolution of mathematical knowledge since the Paleolithic. Although observation capabilities are noted in many species, it reaches a more sophisticated form with hominids, followed by the capabilities of comparing, of classifying, of evaluating quantitatively and qualitatively, of counting and measuring and of inferring, which are the first steps for the emergence of mathematical thinking (D'AMBROSIO; ALMEIDA, 2017).

\footnotetext{
${ }^{4}$ The Metalogicon of John of Salisbury. A Twelfth-Century Defense of the Verbal and Logical Arts of the Trivium, translated with an Introduction \& Notes by Daniel D. McGarry, Gloucester, MA: Peter Smith, 1971; Booh III, p.167.
} 
With this historiographical posture, I discuss knowledge and behavior as a dyadic adaptive system, which, as discussed above, gradually transforms its own cognitive and social bases, to satisfy the human pulsions of survival and transcendence.

In all living beings, survival of the individual and continuation of the species is the satisfaction of vital needs and strategies, dictated by physiological mechanisms intrinsic to life. The satisfaction of the survival drive takes place instantly, here and now, which is by many called instinct. Among the order of primates, the hominid family emerged about 14 million years ago and the evolutionary process led to the genus ${ }^{5}$ homo, which include the species homo neandertalensis, homo denisovanense, homo sapiens and several others. All were extinct, exept homo sapiens, which survived to this day, of which we are physically, biologically and intellectually differentiated as the sub-species homo sapiens sapiens. In the evolutionary process, families and sub-families of bipeds, australopithecians and many others moved in groups and the first steps began to appear in the conscious development of the drive for transcendence, to go beyond survival. Since the beginning, the homo gender has been formed by omnivorous individuals, who live in tribes and develop social behavior, vocalization and complex gestures, in addition to revealing parental care, which could be considered a proto-education. The here-now gives rise to the where-when and they begin to question and try to understand and explain facts and phenomena, to try to deal with situations and problems that arise in the conduct of daily life. They generate and organize strategies to understand and explain and deal with situations and socialize these strategies. About 1 million years ago, this process begins with the appearance of homo denisovanense, homo neanderthalensis and other species, including the most recent, homo sapiens and remarkable inventions, such as the development of communal shelters, discovering and learning to control fire, developing language, manufacturing instruments and starting to recognize leaders. Thus, between individuals in groups emerged hierarchy.

In this evolutionary scenario, knowledge and behavior are developed, which are the strategies to satisfy the drives for survival and transcendence. These strategies are generated and mentally organized by individuals, are socialized, transmitted and disseminated in similar groups. This process is contextualized and, of course, holistic, integrating resources of different natures: human resources (knowledge, practices, work,

\footnotetext{
${ }^{5}$ In the hierarchy of biological classification, genus comes above species and below family. I follow, for this classification, the taxonomy still used today proposed by the Swedish botanist Carl Linnaeus (17071778) to define the groups of organisms biological based on common characteristics.
} 
hierarchies), inert resources (land, instruments) and living resources (seeds, planting and harvesting, animals and domestication). Integrated, they give rise to economic systems, governance systems and systems of power, thus constituting a complex society. They share knowledge and behavior, knowledge and actions, the result of socialization, which are transmitted and disseminated, and determine the behavior of the group, which submits to an agreement on ways of acting, on language and ways of relating, on values and rituals. Naturally, the behavior agreed by the group provokes the search for more knowledge by the group. This sharing leads to the concept of culture.

What is culture? Culture is a ubiquitous concept. There are many definitions of culture. Essentially, it consists of shared knowledge, a system of shared meaning, a manifestation of the unconscious mind and it backs organizational systems in every area. My definition is as follows: culture is the set of behaviors agreed by a group and of knowledge shared and intrinsic to the group, which implies common language, myths and accepted values and "knowledge/practices" of the group. Culture is a social concept, central to studies of human evolution. Recent research by primatologists has provided important indicators of the process of human cultural diversification and its impact on human adaptation. The process of evolution of knowledge is slow and fragmented and is subject to encounters between groups with different cultures. These distinctions can be vertical, that is, intracultural, especially between groups distanced in time (ancestrals and new generations), and horizontal, that is, intercultural. Dealing with these vertical and horizontal encounters is the subject of the transdisciplinary and transcultural study of the cultural dynamics of the encounters (D'Ambrosio, 2007).

Of course, there may be disagreements between different cultures. But there can also be disagreements between individuals and even sub-groups within the same culture. The distinction between large cultural groups and sub-groups is tenuous, sometimes difficult to identify. We could even go so far as to consider each individual as having their individual culture. Pure illusion. Culture is a social concept. There is no life without interaction with nature and with others, therefore with society.

There are exceptional cases, such as autism in varying degrees, which may disturb this interaction. This is a theme that is much explored in fiction, sometimes inspired by real events. There are legends of individuals who develop without interaction with other humans. An example, in Roman mythology, is the case of Romulus and Remus, founders of Rome. Other examples are Mogli, the main character of the novel The Jungle Book, by the English writer Rudyard Kipling (1865-1936), and the young Kasper Hauser, main 
character of the film/book The Enigma of Kasper Hauser, by Werner Herzog, 1974. This book is an excellent study of social psychology. The novel is based on the real life of an enigmatic young German, called Kasper Hauser (1812 -1833) who says, in his autobiography, that a few days after birth was locked in an attic, fed only with bread and water, without ever having seen a human being. Freed as a teenager in a public square, at the age of 16 he saw other human beings and only then interacted with other individuals. He was murdered in 1833, an as yet unsolved crime. His autobiography is contested by many historians, as false. Even though, the scholarly reflections of Werner Herzog on the development of knowledge is relevant. According to Herzog, he learned to speak, to read and to write. Interesting is the mention that Kasper Hauser used a logic of his own when inquired by the teacher to solve a mathematical problem.

This reveal Werner Herzog's recognition that individuals generate knowledge, in particular logic knowledge, hence mathematical knowledge. This means knowledge is generated by individuals, not aa a social construct. This is a recurrent theme in philosophy, brought to attention in the controversy Piaget-Vygotski. Kasper Hauser and other mythological and fictional characters show the difficulty of understanding how much a human being can maintain his own and exclusive cultural traits. I believe it is impossible. Generation and acquisition of knowledge, particularly mathematical knowledge, are universal phenomena and the result of environmental interaction. The recognition of this is implicit in the name Humanistic Mathematics, which increasingly enters the academic world.

Knowledge is a set of intellectual actions generated and organized by the individual, in response to his interaction with the environment, which includes nature and other individuals, and which cannot be captured by others. These I call Mentifacts, i.e., thoughts, ideas, emotions, feelings, desires, intentions and many other intellectual categories that are generated and organized by each individual and are exhausted in the individual, they can't be captured by other individuals. The desire to know what the other is thinking is characteristic of all human beings. The search to know what the other is thinking has led, throughout history, to strategies such as torture, serums of truth, confession, threats, psychoanalytic techniques. Nothing is achieved unless individuals transform their mentifacts into artifacts (gestures, vocalizations, language, drawings, writings, instruments, arts, objects of all kinds). ${ }^{6}$ The transition from mentifacts to

${ }^{6}$ I owe these words, as well as socifacts, to David Bidney: On the Concept of Culture and Some Cultural Fallacies. American Anthropologist New Series, [S.I.], v. 46, n. 1, p. 30-44, jan./mar., 1944. 
artifacts is a mental process that I call reification, which is essentially moving from abstract to concrete, or from ideas to things. ${ }^{7}$

How has reification, in the sense that I adopt, developed throughout history? In other words, how did cultures evolve? To study the evolution of cultures, the classification proposed in 1820 by Christian Jürgensen Thomsen (1788-1865), which is the Three Ages System, dividing the prehistory human in three consecutive periods: Stone Age, Bronze Age and Iron Age, continues to be adopted, with several sub-periods.

\section{Mathematics and cultures}

Although the following discussions are part of General History of Civilizations and are well known, I will select and organize them in a convenient manner for my narrative.

How it all began? In all cosmogonies, there is some supernatural entity, above human comprehension, responsible for the creation out of chaos, out of nothing. I give a very synthetic description of two traditions, a creationist and an evolutionist. In Abrahamic traditions, creation begins when God determines Fiat Lux. From this tradition and all other traditions, the creation myths start from nothing, the universe is created and it culminates with the creation of man. In scientific explanations there is the big bang, which says that from a primordial atom, there was a big expansion, which continuesis. I adopt this explanation. The beginning of this expansion would have occurred circa 13.7 billion years ago. About 5 billion years ago, some products of this expansion began to consolidate and the Sun and the Solar System appeared. The Earth was formed around 4.54 billion years ago and about 4.1 billion years ago chemical elements combined, initiating the phenomenon of life. About 3.8 billion years ago appeared LUCA (Last Universal Common Ancestor), the ancestor common to all of us, and about 1.7 billion years ago, multicellular organisms, with differentiated cells to perform specialized functions, began to appear. Invertebrate and vertebrate animals emerged about 525 million years ago. About 251 million years ago Archosaurios gave rise to dinosaurs and other sauros. The first terrestrial plants date from about 450 million years ago and between 130 and 90 million years ago, flowering plants and social insects appeared. The sauros were extinct 65 million years ago. Mammals have rapidly increased in size and diversity

\footnotetext{
${ }^{7}$ I use the word reification in this very elementary sense, unlike the meaning given to this word by Karl Marx and by critics of the technocratization of society, such as Theodor W. Adorno.
} 
and one of these differentiations are primates. Among them, the family of hominids appeared, about 14 million years ago, beginning an evolutionary process that led to the genus homo and to many species, like homo neanderthalensis, homo denisovanense, homo sapiens and several others. Among groups of these species there is evidence of a proto-trade aiming at the acquisition of obsidian and other raw materials necessary for an emerging technology. All these species were extinct with the exception of homo sapiens, of which we are physically, biologically and intellectually differentiated as a sub-species, homo sapiens sapiens, differentiated into cultural groups, as already discussed above.

War strategies, which evidently involve mathematics, are present since mythological times. One of the main characteristics of cultural groups is their mythology, explaining how they came into being. These explanations, starting from cosmogonies, reveal early conflicts between individuals and groups of entities (gods and humans), all of a mythological character. In every tradition, there are oral narratives of how the conflicts resulted in wars. These have been incorporated into sacred texts, which are anchored in mythologies assimilated by different cultural traditions. Examples are the Trojan War, in which gods and men participated; the Battle of Kurukshetra, between the Pandavas and Karauvas families in India; the war between the Manuchin and his uncles Salm and Tur in old Persia; the more recent exodus of Hebrews from Egypt. All of them reveal strategies followed by warring groups. But there are no archaeological sites with evidence and details of these episodes. They are part of narratives of different traditions, which eventually, much later, have been compiled as books of sacred character.

The oldest archaeological remains of wars may be from the Battle of the River Tollens, near the Baltic Sea, about 3,200 years ago, which is recorded in the history books. There was no writing. Organized groups, with thousands of individuals, advocating what the armies would be, went into shock on a crossing of the Tollens River. It was not a skirmish between local clans. Thousands of warriors came together and organized, planned, trained and, well armed, engaged in a brutal struggle, leaving countless dead and mutilated, in the order of thousands. The fighting may have lasted a long time, using weapons made from wood, stone chips and bronze, a metal that was beginning to gain importance and became decisive in the development of military technology. Surely, a conflict of such proportion required strategies, mainly training and planning. An early mathematics of war. What were the motivation for this conflict? Undoubtedly, were territorial disputes related to trade routes. This may be recognized as an early concept of territory (CURRY, 2016). 
About 10,000 AP, homo sapiens sapiens, then hunter-gatherer, who already occupied the entire planet, acquired a sense of territorial identification. In all mythologies we find reference to this stage, as "private" properties, inaccessible to outsiders. Most explicit are the territorial demarcation of Mount Olympus, in Greek Mythology, as the home of the gods, and the Garden of Eden, in Mesopotamia, in the Abrahamic traditions. Thus emerged the concept of a demarked territory. In this period, agriculture and the domestication of animals were developing, which resulted in stable human settlements and production. Mathematics was decisive in these advances, as related by Herodotus. Excess of production gave origin to a primitive commerce, bartering, which caused the weakening of the territorial demarcation of "private" properties and gave origin to protourban settlements, which developed into proto-cities. Primitive forms of habitation arose and groups discovered the technique of producing ceramics by heating the clay, learned to convert natural fibers into threads and fabrics, built dwellings and started working with metals to produce instruments. Individuals skilled with these innovations were recognized as distinct from farmers and ranchers, and constituted a social class, the artisans. Thus emerged the social division of labor. Around 6,000 BC, emerged groups occupying larger territories which we may call proto-states. the classes. Soon emerged a form of leadership in these groups and they organized themselves in the form of cities and proto-states. Nest phase these proto-states became stronger and rivalry among neighboring communities was permanent. A governing structure and some forms of law became necessary. Appeal to gods was the frequent form of legitimation, which resulted in the emergence of priestly classes. Keeping power required organized military forces. These proto-states gave rise to more complex organization, the kingdoms, with a sophisticated hierarchy of governance, of heritage and of government bureaucracies to facilitate their administration. Priesthood became much more powerful in the support of the government.

Cities are characterized by a large population and occupation of a given territory, where the divisions of labor and social classes are distinguished. There is subordination to common deities and the emergence of a government elite, made up of a priestly class recognized as divine representatives and the kings as divinities, and their circle of auxiliaries, mainly priesthood. Monuments, temples and palaces appear dedicated to divinities and to the governmental elite. As a result, we have the development of sciences and arts, particularly engineering and architecture, agriculture, calendars and writing, and public administration, and also individual men or women reputed to have special powers for good or evil, including in matters of diseases and their cures. All these skills, as 
organized fields of knowledge were supported by arithmetic, geometry, astronomy. Individuals capable of dealing with these different forms of knowledge were recognized by the communities as specialists and professionals, constituting a form of elite. They organized themselves as classes and prepared other individuals for the same functions. We might say a proto-education emerged.

A class of specialists in writing, the scribes, were responsible for registering knowledge. This class are well recognized in Egypt and Babylonia are well studied, writing hieroglyphs in papyri and cuneiform writing in clay tablets. The education of scribes is fascinating. We have to mention the equivalent to scribes in the New World, particularly the Quipucamayuq, a sort of accountant and scribe in the Inca tradition. It is difficult to say whether they were relevant

for cultic practices, or for pure register, or for studies and inventions, or used in the education and information of professional groups.

Scribes in Ancient Iraq were responsible for registering what is probably the earliest classic in literature, the Epic of Gilgamesh, in which we find the first structured mathematical knowledge with practical purposes. For a detailed account of the role of scribes and the detais of the Epic of Gilgamesh, see my paper on Ea, Pythagoras and Avatar. A philosophical posture permeates this paper (D’AMBROSIO, 2010).

The surplus of agricultural and artisanal production that meets the needs of the governmental elite and the population, becomes the object of trade with other cities and even with distant states.

The proto-states of Ancient Iraq, the Nile-Sahara and, further to the East, the Indus River Valley (present-day India) and the Huang and Yang-Tse River Valley (present-day China) are well studied. There is growing attention to the New World, whose development was later. Little is known about urban life. More is known about ceremonials, showing a religious/governmental organization similar to what happened long before in the Old World.

Agriculture and livestock were essential in practically the entire world. As a result, there is a need for water and irrigation. There is evidence of irrigation works about 8,000 years ago in Cuzistan, now Iran. In the same period, irrigation works took place in various regions of the world. Particularly in Ancient Iraq, where, at the beginning of the Bronze Age, where we find the first groups that organized themselves as what we could call city. Uruk is an example. 
Some individuals were concerned about thinking about broader aspects of human nature. These individuals congregated in delimited and exclusive spaces, lately denominated academies. Particularly, mathematics was a focus of their thinking. Although mathematical objects originated in the life-world, the mathematics in the academy were not those of everyday life. Those thinkers constituted, in every culture, the elite The other members of the population were concerned with public affairs: artisans, professionals, builders, architects, engineers and many other tasks for daily life. They are historically referred as the invisible society. Surely, they had knowledge of the mathematics necessary to perform their tasks, some requiring sophisticated mathematics, like the construction of temples, palaces and irrigation systems. But the workers were not part of the elite in academies. In modern historiography, increasing attention is given to the unnamed intellectuals, part of the invisible society. It is a difficult to deny that a few academicians were common people, even slaves, patronized in some way, and some academicians participated, in some ways, in public affairs. A good example is Archytas, of Tarentum, who was a general and politician and at the same time an academician, responsible for advances in mathematics [duplication of the cube, proofs by reductium ab absurdum] and in Pythagorean philosophy (D'AMBROSIO, 2005). Another example is the life and works of Archimedes. It is impossible to deny mutual influence of academic mathematics and daily-life mathematics. This is clearly shown in Marcus Vitruvius Pollio (c.80 BC-c.15 BC), author of the classic De Architecture Liber Decem (VITRUVIUS, 1999). Thus emerged a philosophy of mathematics which combined a dual objective: the social impact of knowledge and the pursue of ideal concepts.

Roman position with respect to knowledge, comparing with Greeks, as stated by Marcus Tullius Cicero (106-43 a.C.), clarifies the philosophical regard of mathematics, as seen in the book of Vitruvius. Cicero says:

\footnotetext{
On at last securing a complete or at any rate a considerable release from the toils of advocacy ${ }^{1 \mathrm{a}}$ and from my senatorial duties, I have once more-chiefly, Brutus, on your encouragement-returned to those studies, which, though stored in memory, had been put aside through circumstances, and are now revived after a long interval of neglect. My view was that, inasmuch as the system and method of instruction in all the arts which have a bearing upon the right conduct of life is bound up with the study of wisdom which goes by the name of philosophy, it was incumbent on me to throw light upon that study by a work in the Latin tongue; not that philosophy could not be learnt from Greek writers and teachers, but it has always been my conviction that our countrymen have shown more wisdom everywhere than the Greeks, either in making discoveries for themselves, or else in improving upon what they had received from Greece-in such subjects at least as they had judged worthy of the devotion of their efforts. ${ }^{2}$ For morality, rules of life, family and household
} 
economy are surely maintained by us in a better and more dignified way (Cicero, 1927, p. 1).

Undeniably, we see a practical position and no concerns about their gods, until the $3^{\text {rd }}$ century, with the growth of Christianity, superimposing a God and dispensing pagan philosophers. Some philosophers are important by their treatment of mathematics as immersed in a broad concept of the seven liberal arts [grammar, rhetoric, dialectic, arithmetic , geometry, music, astronomy] in Medieval Culture. Examples are Martianus Minneus Felix Capella, a Latin prose writer of the $5^{\text {th }}$ century, who wrote, between $c .410$ c.420, a systematic treatise of the seven liberal arts, an elaborate didactic allegory entitled De nuptiis Philologiae et Mercurii (On the Marriage of Philology and Mercury), a title that reveals pagan presence among medieval scholars. Another philosopher is Anicius Manlius Severinus Boëthius (c.477-524), who wrote about the quadrivium [arithmetic, music, geometry and astronomy - the books on music and astronomy are lost]. Also important, with a broader objective, covering not only the seven liberal arts, but knowledge in practical areas, particularly medicine, is the encyclopedic work Etymologies, by Isidore of Seville (c.500-636). This is briefly the scholarly scenario of the Early Middle Ages. The philosophical support for all these works was scholasticism, an intellectual exercise joining faith, identified with Catholic Theology, and reason. This prevailed until after the Crusades, the period usually called the Late Middle Ages. There was a recuperation of Greek Philosophy and Mathematics, as kept and advanced by Arabic scholars. In the monasteries there was much restrictions to this "new" scholarship arriving in Europe, but in the universities, thinkers embraced these ideas. They started to reinvent ancient physics and political philosophy as godless pursuits whenever they could manage. Particularly important are Thomas Bradwardine (c.1300-1349), of Merton College of Oxford University, where he and collaborates paved the way to Descartes, Galileo, Kepler, Newton, Leibniz, among many others. Intellectuals of all lines, philosophers, scientists, sociologists, writers, artists, all became interested in discussing the ideas of Newton, Leibniz and mathematicians in general. We may say, mathematics became the focus of interest of the European intellectuality.

Philosophers like François-Marie Arouet, Voltaire (1694-1798), Johann Gottfried von Herder (1744-1803), Immanuel Kant (1724-1804), Georg Wilhelm Friedrich Hegel (1770- 1831), Johann Wolfgang von Goethe (1749-1832), Karl Marx (1818-1883), Friedrich Nietsche (1844-1900) all have, in some measure, acquired or rejected the ideas developed by Newton, Leibniz and mathematics. Particularly controversial is the position 
of Goethe, against scientists and philosophers, claiming that Galileo, Descartes, Newton, Leibniz and followers were attempting to denude nature of its living forms and to seclude human consciousness in their mathematical theories. In a way, Goethe anticipates phenomenology. It is also notable what Nietsche affirmed, in The Gay Science:

Let us introduce the refinement and rigor of mathematics into all sciences as
far as this is at all possible, not in the faith that this will lead us to know things
but in order to determine our human relation to things. Mathematics is merely
the means for general and ultimate knowledge of man (NIETSCHE, 2001, p.
148).

But, in his entire production, we recognize Nietsche's critique of European rationality, which was later shared by Edmund Husserl (1859-1938), claiming that the origin of the difficult times in Europe were due to the fact that rationality had missed life. Their position, paving the way to phenomenology, was to restore meaning of life.

Newton's Principia gave origin to what has been called the Age of Enlightenment, which anticipates the Industrial Revolution and the political turmoil in Europe and in the colonies, particularly in New England. Specifically, Independence of the Thirteen English Colonies in America and the French Revolution. This was followed by the Bonaparte period, which was rich in the development of Mathematics. Many historians call this the siècle d'or des mathématiques. Publications became intense in national languages, which led to the appearance of abstracting journals like the Jahrbuch über die Fortschritte der Mathematik, in 1868. I believe that this was the first time that Philosophy was recognized as part of Mathematics, since one section was devoted to History an Philosophy. Curiously, the ICM 1897/First International Congress of Mathematicians, 1897, Zurich, nor ICM 1900, Paris, had a section on the Philosophy of Mathematics. Only in ICM 1908, Rome, philosophy appears as Questioni filosofiche, storiche, didattiche. In ICM 1912, in Cambridge, a section on History and Philosophy is in the program. Since then, Philosophy of Mathematics is recognized as an established research area in Mathematics, with many sub-areas, such as Platonism, Pragmatism, Empiricism, Logicism, Intuitionism, Formalism, Predicativism and many others.

\section{As a conclusion}

I discussed the evolution of mathematics as an human endeavor, with a holistic historiographic stance. There are numerous conceptions and definitions of knowledge and behavior. 
My tactics throughout the chapter was to examine the evidence for the creation of more or less systematic inquiries in different societies and at different periods, to investigate why they were defined or understood in the ways they were, on what basis particular individuals or groups claimed special expertise, and what lead to a professionalization.

I owe much to the way G.E.R. Lloyd approaches the concept of disciplines with an historiographical support in his book Disciplines in the Making. In the first chapter he discusses "what is philosophy" and in the second chapter is "what is mathematics". He appeals to etymology, saying that the origins of the words philosophy and mathematics can be traced to Greek roots. Philosophy always considers things that arouses human mind and leads to think.

The word mathematics is more complex. It comes from the Ancient Greek máthēma, meaning "that which is learnt".The word for "mathematics" came to have the narrower and more technical meaning "mathematical study" and also astrology, sometimes astronomy, even in Classical times, particularly in the Early Medieval Latin, as used by Augustine. The meaning gradually changed, as the support of philosophia naturalis and, around the $15^{\text {th }}$ century, it acquired the meaning we give it in nowadays.

The study of Mathematics is of interest to all disciplines in the sciences, engineering and humanities, as well in the arts and the religion, and of psychology and cognition in general. Mathematics is of great interest to philosophers and vice versa, since one of the main philosophical task is to reflect upon the basic assumptions, inference, patterns and theories, which are the essence of mathematics.

\section{Rerefences}

ALDER, K: History's Greatest Forger: Science, Fiction and Fraud Along the Seine. Critical Inquiry, [S.I.], v. 30, p.702-716, Summer. 2004.

ARENAS, M. G. Book Review of Katrina B. Olds: Forging the Past. Invented Histories in Counter-Reformation Spain. Yale University Press, 2015. In: Erudition and the Republic of Letters 2, 2017, p.459-463.

BAILYN, B. The Challenge of Modern Historiography. The American Historical Review, [S.I.], v. 87, n. 1, p. 1-24, feb. 1982.

BLUMENTHAL, O. Lebensgeschichte. In: Huberts, D. Gesammelte Abhand-lungen 3. [S.I], 1935. p. 388-429.

BOULDING, K. General Systems Theory. Management Science, [S.I.], v. 2, n. 3, p.197-208 apr. 1956. 
CICERO, M. T. Tusculan Disputations. Translated by J. E. King. Loeb Classical Library 141. Cambridge, MA: Harvard University Press, 1927.

CURRY, A. Slaughter at the Bridge. Science, [S.I.], v. 351, n. 6280, p. 1884-1889, mar. 2016.

D'AMBROSIO, U. Ethnomathematics and its Place in the History and Pedagogy of Mathematics, FLM/For the Learning of Mathematics, [S.I.], v.5, n.1, p.44-48, feb. 1985.

D'AMBROSIO, U. Review of Archytas of Tarentum: Pythagorean, Philosopher and Mathematician King. Cambridge: Cambridge University Press, 2005.

D'AMBROSIO, U. The Cultural Dynamics of the Encounters: Ethnoscience and Ethnomathematics, Traditions of Science. Cross-Cultural Perspectives. Essays in Honour of Prof. B.V. Subbarayappa, Purushottama Bilimoria and Melukote K. Sridhar, editors, Munshiram Manoharlal, Publishers Pvt, Ltd, New Delhi, 2007. p.187-196.

D'Ambrosio, U. From Ea, through Pythagoras, to Avatar: different settings for mathematics. Mathematics in Different Settings. In: PROCEEDINGS OF THE 34TH CONFERENCE OF THE INTERNATIONAL GROUP FOR THE PSYCHOLOGY OF MATHEMATICS EDUCATION/PME, 34, 2010, Belo Horizonte. Proceedings... MG, Brazil, 2010, v.1. p.1-20.

D'AMBROSIO, U. The Metaphor of Epistemological Cages and an Educational Proposal Perspectives of Mathematical Education, Mato Grosso do Sul, v. 9, n. 20, p. 222-234, 2016.

D'AMBROSIO, U.; ALMEIDA, M. de C. A. Ethnomathematics and the Emergence of Mathematics. In: ADAMS, J. W.; BARMBY, P.; MESOUDI, A. (ed.). The Nature and Development of Mathematics: Cross Disciplinary Perspectives on Cognition, Learning and Culture. New York: Routledge, 2017. p.69-85.

GODFREY-SMITH, P. Other Minds The Octopus, the Sea, and the Deep Origins of Consciousness. New York: Farrar, Straus and Giroux, 2016.

ILIFFE, R: Priest of nature: the religious worlds of Isaac Newton. New York: Oxford University Press, 2017.

LAKATOS, I. History of Science and its Rational Reconstructions. Boston Studies in the Philosophy of Science, [S.I.], v. VIII, p.91-136 1971.

LLOYD, G.E.R. Disciplines in the Making Cross-Cultural Perspectives on Elites, Learning, and Innovation. New York: Oxford University Press, 2009.

NIETSCHE, F. The Gay Science. Translated by Josefine Nauckhoff. New York: Cambrige University Press, 2001.

SCHOPENHAUER, A. On Thinking for Oneself. In: Parerga and paraliponema: short philosophical essays, 2 volumes, translated by E.F.J. Payne. New York: Oxford University Press, 1974, p;491-500.

VARELA, F. J.; THOMPSON, E.; ROSCH, E. The Embodied Mind: Cognitive Science and Human Experience. Cambridge: M.I.T. Press, 1991.

WILLIANSON, T. The Philosophy of Philosophy (The Blackwell/Brown lectures in philosophy), Maiden MA: Blackwell Publishing Ltd, 2007. 